\title{
A Knock-In Reporter Model of Batten Disease
}

\author{
Steven L. Eliason, ${ }^{1 \star}$ Colleen S. Stein, ${ }^{1 \star}$ Qinwen Mao, ${ }^{1}$ Luis Tecedor, ${ }^{1}$ Song-Lin Ding, ${ }^{1}$ D. Meredith Gaines, ${ }^{1}$ and \\ Beverly L. Davidson ${ }^{1,2,3}$ \\ Departments of ${ }^{1}$ Internal Medicine, ${ }^{2}$ Neurology, and ${ }^{3}$ Physiology and Biophysics, University of Iowa, Iowa City, Iowa 52242
}

Juvenile neuronal ceroid lipofuscinosis is a severe inherited neurodegenerative disease resulting from mutations in CLN3 (ceroidlipofuscinosis, neuronal 3, juvenile). CLN3 function, and where and when it is expressed during development, is not known. In this study, we generated a knock-in reporter mouse to elucidate CLN3 expression during embryogenesis and after birth and to correlate expression and behavior in a CLN3-deficient mouse. In embryonic brain, expression appeared in the cortical plate. In postnatal brain, expression was prominent in the cortex, subiculum, parasubiculum, granule neurons of the dentate gyrus, and some brainstem nuclei. In adult brain, reporter gene expression waned in most areas but remained in vascular endothelia and the dentate gyrus. Mice homozygous for $C \ln 3$ deletion showed two hallmark pathological features of the neuronal ceroid lipofuscinosises: autofluorescent inclusions and lysosomal enzyme elevation. Moreover, CLN3-deficient reporter mice displayed progressive neurological deficits, including impaired motor function, decreased overall activity, acquisition of resting tremors, and increased susceptibility to pentilentetrazole-induced seizures. Notably, seizure induction in heterozygous mice was accompanied by enhanced reporter expression. This model provides us with the unique ability to correlate expression with pathology and behavior, thus facilitating the elucidation of CLN3 function and the pathogenesis of Batten disease.

Key words: Batten disease; juvenile neuronal lipofuscinosis; JNCL; knock-in mouse; $\beta$-galactosidase; lysosomal storage diseases; CLN3

\section{Introduction}

The neuronal ceroid lipofuscinosises (NCLs) are a collection of recessive inherited neurodegenerative diseases (Santavuori, 1988). Juvenile-onset NCL (JNCL), often called Batten disease, results from mutations in $C L N 3$ (ceroid-lipofuscinosis, neuronal 3 , juvenile) and represents the most common form of NCL (Wisniewski et al., 1988; Lerner et al., 1995). Clinical manifestations of JNCL typically onset at 6-8 years of age and include visual impairment progressing to blindness, followed by seizures, behavioral abnormalities, and cognitive and motor decline. Patients succumb to disease in the second or third decade of life. A pathological hallmark of the NCLs is the accumulation of lipidrich autofluorescent inclusions in multiple cell types.

CLN3 is a 438-amino-acid, hydrophobic transmembrane protein. In non-neuronal cells, CLN3 localizes primarily to endosomes and lysosomes (Haskell et al., 2000; Ezaki et al., 2003; Mao et al., 2003; Kyttala et al., 2004), whereas in neurons, CLN3 is also detected in vesicular structures at synapses and along neurites (Haskell et al., 2000; Luiro et al., 2001; Kyttala et al., 2004). These findings suggest that in most/all cell types, CLN3 performs

\footnotetext{
Received April 16, 2007; revised July 17, 2007; accepted July 18, 2007.

This work was supported in part by a grant from the Batten Disease Support and Research Association and the Roy J. Carver Trust. We acknowledge Sheena Ries, Ines Martins, and Xiaohua He for technical assistance and Michael Chang for help with the tremor assay. We also thank the Central Microscopy and Gene Targeting Cores at the University of lowa.

*S.L.E. and C.S.S. contributed equally to this work.

Correspondence should be addressed to Dr. Beverly L. Davidson, Department of Internal Medicine, 200 EMRB, University of lowa, lowa City, IA 52242. E-mail: beverly-davidson@uiowa.edu. DOI:10.1523/JNEUROSCI.1710-07.2007

Copyright $\odot 2007$ Society for Neuroscience $\quad$ 0270-6474/07/279826-09\$15.00/0
}

a basic function related to the lysosome, whereas in neurons, CLN3 may take on additional specialized tasks.

Information regarding the tissue distribution of CLN3 is limited, particularly for the mouse. In adult murine brain, immunostaining and/or in situ hybridization for transcript localizes CLN3 to neurons in the cortex, hippocampus, cerebellum, thalamus, and hypothalamus (Luiro et al., 2001; Cotman et al., 2002). Immunoblot of lysates from murine tissues shows abundant CLN3 in liver, kidney, and spleen and low amounts in pancreas and brain (Ezaki et al., 2003). A study on human tissues showed low CLN3 levels in the liver but high levels in brain by immunoblot of tissue lysates (Margraf et al., 1999).

Unambiguous detection of murine CLN3 in vivo has been hampered by low endogenous levels combined with a lack of suitable high-affinity antibodies. In the current study, we describe a reporter knock-in with nuclear-targeted bacterial $\beta$-galactosidase (encoded by Escherichia coli lacZ) replacing exons 1 through 8 in the murine $C \ln 3$ locus. $\beta$-Galactosidase transcription in the recombinant allele is controlled by native sequences $5^{\prime}$ to the $\operatorname{Cln} 3$ coding region, and the homozygous knock-in mice are CLN3 deficient.

Two other mouse models of JNCL are under current investigation. In one model, the $3^{\prime}$ end of exon 1 through exon 6 has been replaced with a selectable marker, $\operatorname{Cln} 3^{\Delta e x l-6}$ (Mitchison et al., 1999). The other model is a knock-in of the common JNCL mutation, an exon 7-8 deletion $C \ln 3^{\operatorname{sex} 7 / 8}$ (Cotman et al., 2002). In that model, splicing around the mutation generates variant transcripts, one of which encodes a mutant CLN3 with a native C terminus. Although study of these models undoubtedly contributes to our understanding of the disease process, our reporter model provides us with the unique ability to track CLN3 expres- 

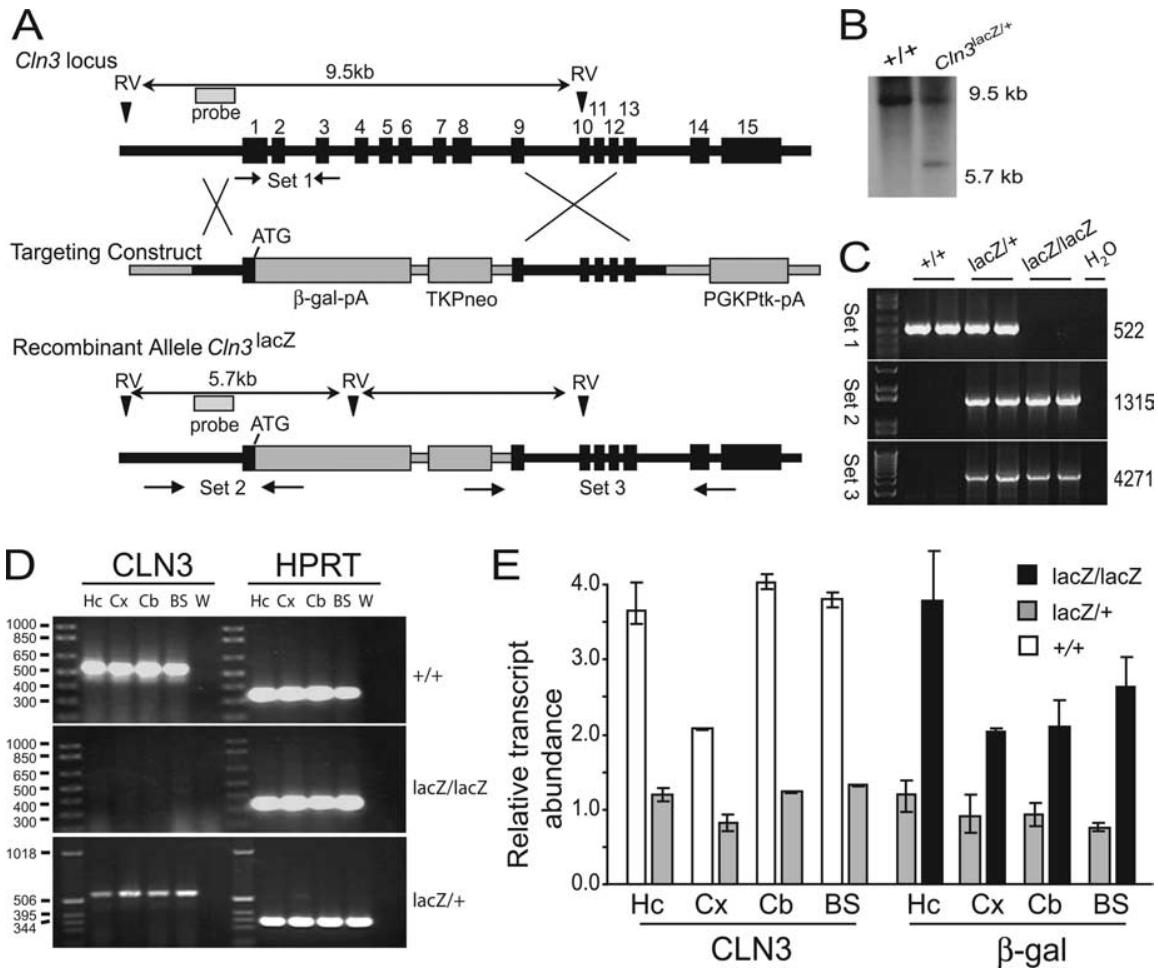

Figure 1. Generation of CLN3 reporter mice. $\boldsymbol{A}$, Targeting construct and strategy for homologous recombination. $\boldsymbol{B}$, Representative Southern blot from $\mathrm{Cln} 3^{+/+}$and $\mathrm{In} 3^{\operatorname{lac} Z /+}$ genomic DNA using the probe indicated by the shaded box A.C, Representative genomic $\mathrm{PCR}$ results from $\mathrm{Cln} 3^{+1+}, \mathrm{Cln} 3^{\mathrm{lacZ} /+}$, and $\mathrm{In} 3^{\mathrm{lacZ} / \mathrm{IacZ}}$ mice (2 mice per group) using the primer sets depicted in $\boldsymbol{A}$. D, RT-PCR results for CLN3 (left) and HPRT as control (right) using CDNA isolated from Cln ${ }^{+/+}$, Cln $3^{\text {lacZ/+ }}$, and $C \ln 3^{\text {lacz/lacZ }}$ mice as indicated. $\boldsymbol{E}$, QPCR analysis for relative abundance of $C \ln 3$ and $l a c Z$ transcripts using the same cDNA samples as in $D$; $C \ln 3$ and $l a c Z$ transcripts were below detection levels in $\mathrm{Cln} 3^{\text {lacZ/lacz }}$ and $\mathrm{Cln} 3^{+/+}$samples, respectively. Hc, Hippocampus; $\mathrm{CX}, \mathrm{Cortex} ; \mathrm{Cb}$, cerebellum; BS, brainstem; W, water.

sion temporally and spatially and to correlate expression patterns with pathology and symptoms.

In the current study, $\beta$-galactosidase detection in our mouse model indicates predominant expression in restricted CLN3 regions of the developing and adult brain and in several tissues/cell types not previously reported or emphasized, such as endothelial and epithelial cells. In addition, we describe a progressive disease phenotype in our knock-out mice with respect to pathology, motor control, activity level, tremor, and seizure susceptibility.

\section{Materials and Methods}

Construction of the knock-in allele. The entire murine Cln3 gene was obtained from a $17 \mathrm{~kb}$ lambda P1 clone (a kind gift from Terry Lerner, Molecular Neurogenetics Unit, Massachusetts General Hospital, Charlestown, MA). A $1.2 \mathrm{~kb}$ region including the native $C \ln 3$ translational start and the adjacent 5 ' region was amplified from the P1 template by PCR and cloned into the targeting plasmid. A gene encoding nuclearlocalized $\beta$-galactosidase and simian virus 40 polyadenylation sequences were cloned $3^{\prime}$ to the $1.2 \mathrm{~kb}$ fragment, followed by a neomycin coding sequence driven by the thymidine kinase promoter. A $3.9 \mathrm{~kb}$ HindIII fragment of the P1 clone, which included exons 9-13, was then ligated into the targeting plasmid just downstream of the neomycin cassette. A phosphoglycerate kinase promoter-thymidine kinase cassette was cloned into the region just outside of the $3^{\prime}$ targeting arm to allow for selection against nontargeted integration events. When correctly recombined, this allele replaces $C \ln 3$ genomic sequences from the ATG in exon 1 through exon 8 with the $\beta$-galactosidase and neomycin expression cassettes (Fig. 1A).

SV129 embryonic stem (ES) cells were electroporated with the targeting plasmid, selected with gentamycin (G418, $0.2 \mathrm{mg} / \mathrm{ml}$ ) and gancyclo$\operatorname{vir}(2 \mu \mathrm{M})$, and cloned by limiting dilution. Genomic DNA was isolated from selected clones and screened for correct recombinants using PCR and Southern blot strategies. For PCR, a reverse primer within the $5^{\prime}$ end of the $\beta$-galactosidase coding region ( $5^{\prime}$ gctgtttctggtcttcacccaccg- $3^{\prime}$ ) and a forward primer from the $-1200 \mathrm{bp}$ relative to the ATG region ( $5^{\prime}$-tcaatgcccacaccctcacctatg- $\left.3^{\prime}\right)$ of the $C \ln 3$ gene were used (Fig. 1, primer set 2). For Southern blot, DNA from PCR-positive clones was digested with EcoRV (New England Biolabs, Beverly, MA). Southern blots were performed as described previously (Sambrook et al., 1989) using a probe complementary to a 1 $\mathrm{kb}$ region just upstream of the translational start site. Two positive ES clones, derived from independent electroporations (AX12 and AX19), were injected into blastocysts and implanted into surrogate females to generate two lines of CLN3 reporter mice. Electroporations and blastocyst injections were performed by the University of Iowa Gene Targeting Facility. Tail DNA from pups was screened by PCR and confirmed by Southern blot. Heterozygous reporter knock-in mice $\left(C \ln 3^{\text {lac Z/+ }}\right)$ were backcrossed to C57BL/6 females (The Jackson Laboratory, Bar Harbor, ME), and this was repeated for eight rounds of backcrosses.

Animals. All of the animal studies were approved by the University of Iowa Animal Care and Usage Committee and were conducted in accordance with Institutional and Federal guidelines. Data for this study were generated from the progeny of $C \ln 3^{\operatorname{lac} Z /+} \times C \ln 3^{\operatorname{lac} Z /+}$ matings, after eight backcrosses onto the C57BL/6 strain.

$\beta$-Galactosidase histochemistry and immunostaining. Mice were anesthetized with ketamine and xylazine and were perfused with $2 \%$ paraformaldehyde in PBS, pH 7.2. Tissues were dissected out and postfixed for $2 \mathrm{~h}$ at room temperature, allowed to sink in $30 \%$ sucrose/PBS at $4^{\circ} \mathrm{C}$, and embedded in OCT (Tissue-Tek; Sakura Finechemical, Tokyo, Japan). Ten micrometer sections were cut from a cryostat and mounted on glass plus slides, or $40 \mu \mathrm{m}$ sections were cut and stained as free-floating sections, before mounting on slides. Selected sections were stained overnight with 5-bromo-4-chloro-3-indolyl $\beta$-D-galactosidase (X-gal; Gold Biotechnology, St. Louis, MO), then fresh X-gal was added, and sections were stained an additional $8 \mathrm{~h}$. Some sections were counterstained with Neutral Red $(0.15 \%)$. Sections were air dried for several hours and then coverslipped with Permount for analysis.

Immunohistochemistry was performed on selected sections using polyclonal rabbit anti- $\beta$-galactosidase antibody (BioDesign, Carmel, $\mathrm{NY}$ ), and cell-type-specific antibodies. Sections were blocked by incubation in PBS with $0.1-0.3 \%$ Triton X-100 and $10 \%$ normal goat serum for $1-3 \mathrm{~h}$ at room temperature, followed by incubation in the presence of primary antibodies at $4^{\circ} \mathrm{C}$ over one night (10 $\mu \mathrm{m}$ sections) or two nights (40 $\mu \mathrm{m}$ sections). Sections were washed in PBS and incubated for $2-3 \mathrm{~h}$ with Alexa 488-conjugated goat anti-rabbit and Alexa 568-conjugated goat anti-mouse or anti-rat antibodies (Invitrogen, Carlsbad, CA), washed, and coverslipped with Vectasheild (Vector Laboratories, Burlingame, CA). Mouse monoclonal anti-neuronal-specific nuclear protein (NeuN) (Millipore, Billerica, MA) was used to label neurons, and rat monoclonal anti-CD31 (BD PharMingen, San Jose, CA) was used to label vascular endothelial cells. For confocal analysis, $z$-series were collected and analyzed using a Zeiss (Oberkochen, Germany) LSM510 confocal microscope with LSM software.

PCR. For genotyping, DNA from SV129 ES cell clones, whole embryos, or mouse tail clips or tissues was isolated by standard procedures (Ausubel et al., 1998) and subjected to PCR analysis to distinguish wild-type and recombinant alleles. Three primer sets were used (Fig. $1 A$ ). Primer 
set 1 consisted of a forward primer in exon 1 (5'ctcaatgttatgggaagttctgcg- $\left.3^{\prime}\right)$ and a reverse primer in intron $2\left(5^{\prime}\right.$ gctctcatctttgctccaatcg- $3^{\prime}$ ), to amplify a 522 bp product from only the wild-type allele. Primer set 2 was as described above and amplified a 1315 bp product from only the recombinant allele. Primer set 3 consisted of a forward primer specific for a region of the targeting construct downstream of the TKPneo cassette ( $5^{\prime}$-aggatccgtcgacgttaacggta- $\left.3^{\prime}\right)$ and a reverse primer in the intronic region between exons 13 and $14\left(5^{\prime}\right.$ cctctgacctccatacacacggc- $3^{\prime}$ ), to amplify a 4271 bp product from only the recombinant allele. PCR reactions were run for 35 cycles, using a $60^{\circ} \mathrm{C}$ annealing temperature and elongation times appropriate to the product size. Before being used in these studies, each mouse was genotyped using primer sets 1 and 2 to identify wild-type and recombinant alleles, respectively.

Reverse transcription-PCR. Tissue samples from several brain regions of $C \ln 3^{+/+}, C \ln 3^{\text {lacZ/+ }}$, and $C \ln 3^{\text {lacZ/lac Z }}$ mice were dissected out, and RNA was isolated by the Trizol method (Invitrogen) and further purified using the RNeasy-plus kit (Qiagen, Valencia, CA), which includes a genomic DNA-removal step. One microgram of RNA was reverse transcribed using the Archive kit with random primers (Applied Biosystems, Foster City, CA) in a $50 \mu \mathrm{l}$ reaction. Five microliters of cDNA from this reaction was subjected to PCR using primers designed to detect murine $C \ln 3$ or hypoxanthine phosphoribosyl transferase (HPRT) transcripts in a $50 \mu \mathrm{l}$ reaction. The $C \ln 3$ primers amplified the full-length coding region of CLN3 mRNA (1317 bp), with the forward primer in exon 1( $5^{\prime}$ atgggaagttctgcgggctcgtgg- $\left.3^{\prime}\right)$ and a reverse primer in exon $15\left(5^{\prime}-\right.$ tcaagggaggtgacagaggaagtc- $\left.3^{\prime}\right)$. The HPRT primer sequences were $5^{\prime}$ gttggatacaggccagactttgttg- $3^{\prime}$ for the forward and $5^{\prime}$ gagggtaggctggcctataggct $-3^{\prime}$ for the reverse and amplified a 352 bp product. PCR reactions were run for 35 cycles, using $60^{\circ} \mathrm{C}$ annealing for $C \ln 3$ primers sets and $56^{\circ} \mathrm{C}$ annealing for HPRT primers.

Quantitative PCR. The cDNA samples derived from brains of $C \ln 3^{+/+}, C \ln 3^{\text {lacZ/+ }}$, and $C \ln 3^{\text {lacZ/lacZ }}$ mice and used in standard PCR as described above were also used in quantitative PCR (QPCR) to assess relative amounts of $\beta$-galactosidase and CLN3 transcripts. For QPCR, cDNA was diluted 1:20 in $50 \mu$ l reaction volumes, with Taqman Universal Master Mix (Applied Biosystems). 6-Carboxyfluorescein-labeled primer-probe sets for murine $C \ln 3$ (Mm00487021_ml), $\beta$-galactosidase (custom preparation), and VIC-labeled eukaryotic 18S rRNA endogenous control (Hs99999901_sl) primer-probe sets were purchased from Applied Biosystems. Real-time PCR reactions were set up in triplicate and performed using an ABI prism 7900HT machine (Applied Biosystems). Relative quantitation was performed using the $\Delta \Delta$ Ct method (Applied Biosystems User Bulletin \#2); the calibrator cDNA (sample ascribed a relative quantity of " 1 ”) for $C \ln 3$ analysis was $C \ln 3^{\text {lac } Z /+}$ hippocampus, and the calibrator sample for $\beta$-galactosidase analysis was $C \ln 3^{\text {lacz/+ }}$ hippocampus. Results are presented as mean relative transcript abundance, plus or minus the maximum and minimum values as determined from the replicates.

Analysis of autofluorescence. Three-month-old $C \ln 3^{+/+}$or $C \ln 3^{\text {lacz/+ }}$ mice were anesthetized with ketamine and xylazine and were perfused with $4 \%$ paraformaldehyde in PBS, $\mathrm{pH}$ 7.2. Brains were cut at $10 \mu \mathrm{m}$, mounted, and analyzed by standard fluorescence microscopy. Exposure times were identical for images captured from corresponding fields in $\mathrm{Cln} 3^{\text {lac } Z / l a c Z}$ and $\mathrm{Cln}^{+/+}$sections. For some regions, high-power confocal images were collected in $z$-series using a Zeiss LSM510 confocal microscope with LSM software.

Analysis of tripeptidyl-peptidase-1 enzyme activity. For measurement of tripeptidyl-peptidase-1 (TPP1) activity, $C \ln 3^{\text {lac } Z / l a c Z}$ and $C \ln 3^{+/+}$mice were perfused with PBS, and brains were removed. For this analysis, the cerebellum was used. Tissue extracts were prepared by homogenization in $150 \mathrm{~mm} \mathrm{NaCl}$ and $1 \mathrm{~g} /$ liter Triton X-100 using a disposable pellet pestle and clarified by centrifugation. Supernatants were analyzed for TPP1 activity as described previously after incubation at $\mathrm{pH} 3.5$ to activate TPP1 precursor (Lin et al., 2001). The final activity of TPP1 was calculated by measuring the change in fluorescence units per milligram of protein (Bio-Rad protein assay; Bio-Rad, Hercules, CA).

Rotarod analysis. The accelerating rotarod (Ugo Basile, Comerio, Italy) was used for the analysis of this mouse model. Cln $3^{\text {lacz/lac } Z}$ and
$C \ln 3^{\text {lacZ/+ }}$ mice were tested for rotarod performance at $1,2,6$, and 10 months as described previously (Xia et al., 2004; Harper et al., 2005). For each trial, the rotarod was accelerated from 4 to $40 \mathrm{rpm}$ over $4 \mathrm{~min}$ and then maintained at $40 \mathrm{rpm}$ until completion of the trial, which was terminated after $500 \mathrm{~s}$. Mice were scored as done if they fell off the rod or hung on for two consecutive revolutions without running. Mice were given a single $2 \mathrm{~min}$ habituation before the first trial and then three trials per day for 4 consecutive days, and mice were given a $30 \mathrm{~min}$ rest between trials.

Activity assay. $C \ln 3^{\text {lac } Z / l a c z}$ and $C \ln 3^{\text {lacz/+ }}$ mice were placed in cages with running wheels equipped with magnetic counters (Thoren Caging Systems, Hazleton, PA), and revolutions were measured over a $3 \mathrm{~d}$ period. After a $12 \mathrm{~h}$ habituation period, the magnetic counters were recorded and reset every $12 \mathrm{~h}$ and recorded as P.M. (6:00 PM to 6:00 A.M.) or A.M. (6:00 A.M. to 6:00 P.M.) values.

Clasping. $C \ln 3^{\text {lacZ/lacZ }}$ and $C \ln 3^{\text {lacZ/+ }}$ mice were tested for clasping behavior in a $1 \mathrm{~min}$ tail-hang assay. Individuals were scored positive for clasping if their forelimbs were clenched toward the belly for $\geq 5 \mathrm{~s}$. Three trials per mouse, on consecutive days, were conducted and were done every other month until the completion of the study.

Resting tremors. $C \ln 3^{\text {lac } Z / l a c Z}$ and $C \ln 3^{\text {lac } Z /+}$ mice were analyzed for resting tremor activity using the SR-LAB Startle Response System and a Tremor Monitor detector (San Diego Instruments, San Diego, CA). Briefly, mice were placed in the detection tube and allowed 5 min to habituate. After habituation, the quiescence resting tremor amplitude was measure for each mouse for 20 samplings, each $1 \mathrm{~s}$ in duration and each $5 \mathrm{~s}$ apart.

Pentilentetrazole induction of seizures. Pentilentetrazole (PTZ) (Sigma, St. Louis MO) was given to adult ( 3 months old) $C \ln 3^{\text {lacZ/+ }}$ at a dose of 50 $\mathrm{mg} / \mathrm{kg}$ body weight by intraperitoneal injection to induce seizures. Control $C \ln 3^{\text {lac } Z /+}$ mice received intraperitoneal saline injections. At $24 \mathrm{~h}$ after injection, mice were perfused and brains were fixed and processed for $\beta$-galactosidase histochemistry as described above. In a separate experiment, PTZ was administrated at a dose of $30 \mathrm{mg} / \mathrm{kg}$ body weight to determine the seizure susceptibility of $C \ln 3^{\text {lacZ/lac } Z}$ mice $(n=10)$ compared with $C \ln 3^{+/+}$mice $(n=10)$. Mice were observed for $30 \mathrm{~min}$ after injection, and latency, duration, and severity of seizures were recorded. Seizure-related behaviors were graded using a scale derived from Levkovitz et al. (1999). We defined seizure activity induced by PTZ as follows: grade 1, behavioral arrest, staring; grade 2, myoclonic jerks of limbs, head, neck, or thorax, or head nodding/swaying; grade 3, unilateral clonic activity, front or hindlimb pawing, may result in circling; grade 4, bilateral forelimb tonic or clonic activity (pawing the air, rearing, jumping, wobbling, falling); grade 5 , generalized tonic/clonic activity with loss of postural tone, with or without death.

\section{Results}

\section{Verification of the recombinant genotype}

We used targeted recombination to "knock-in" a nuclearlocalized bacterial $\beta$-galactosidase coding sequence into the $C \ln 3$ locus of mouse ES cells to determine the temporal pattern and tissue distribution of CLN3 expression as well as gain additional insight into the phenotype of a CLN3-deficient mouse. Our targeting replaced most of exon 1 and all of exons 2 through 8 . In the recombinant allele, the intact $5^{\prime}$ promoter region of $C \ln 3$ lies directly upstream of the $\beta$-galactosidase reporter gene (Fig. $1 A$ ). Two lines of mice, AX12 and AX19, were generated from ES clones selected from independent electroporations.

Southern blot and PCR strategies were used to assess the accuracy of recombination in the ES clones and to genotype embryos and pups. For Southern blot analyses, genomic DNA was digested with EcoRV and probed with a $1 \mathrm{~kb}$ probe specific to the promoter region of $C \ln 3$, which binds a $9.5 \mathrm{~kb}$ fragment from the wild-type allele and a $5.7 \mathrm{~kb}$ fragment from the recombinant allele (Fig. $1 A$ ). For PCR, we used three primer sets that amplify products from either the wild-type (set 1 ) or the recombinant (sets 2 and 3) allele (Fig. 1A). Representative results of Southern 

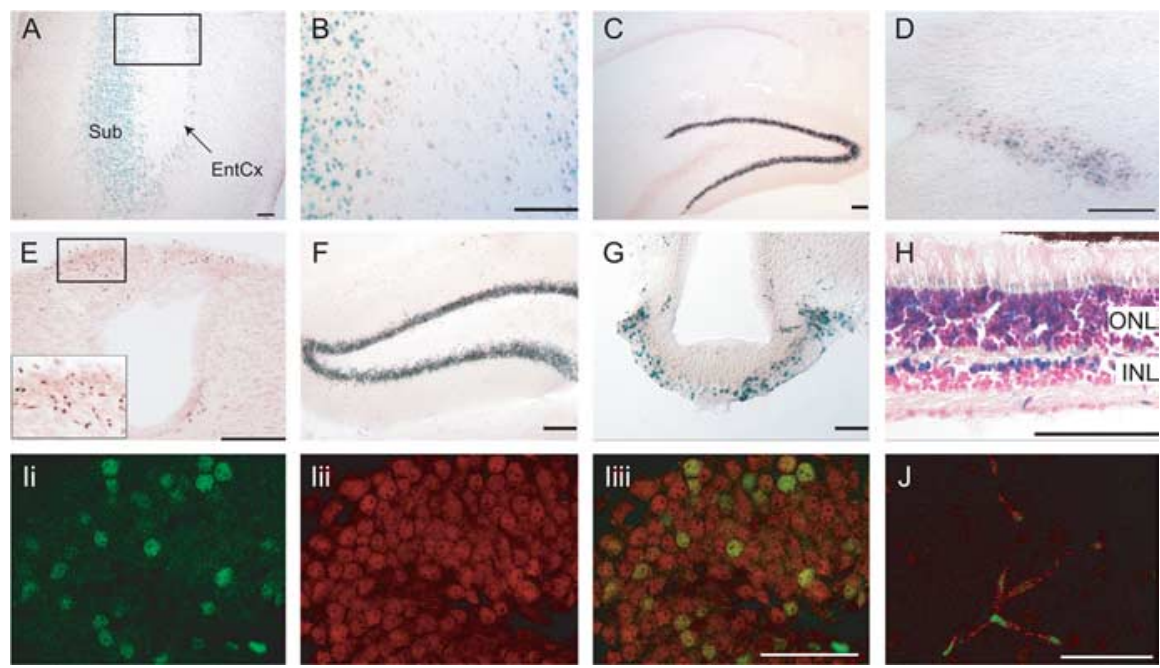

Figure 2. $\quad \beta$-Galactosidase expression in the CNS of postnatal and adult $C \ln 3^{\text {lacz/+ }}$ mice. $A, B$, Subiculum and entorhinal cortex, P7. B is a high-power view of the box in A. C-E, Reporter expression at P21-P27. C, Hippocampus. D, Solitary tract. $\boldsymbol{E}$, Area postrema; inset is high-power photomicrograph of boxed area. $\boldsymbol{F}-\boldsymbol{I}$, Reporter expression in adult ( $\geq 2$ months old) brain. $\boldsymbol{F}$, Dentate gyrus. G, Median eminence. $\boldsymbol{H}$, Retina. I, A confocal image (0.37 $\mu \mathrm{m}$ slice) showing $\beta$-galactosidase (green) (II), NeuN (red) (Iii), and merged channels (Iiii) indicates (In 3 promoter activity in dentate gyrus granule neurons. J, A confocal image (0.37 $\mu \mathrm{m}$ slice) shows localization of $\beta$-galactosidase-positive nuclei (green) in (D31-positive vascular endothelial cells (red) in adult brain. Scale bars: $\boldsymbol{A}-\boldsymbol{H}, 100 \mu \mathrm{m} ; \boldsymbol{I}, \boldsymbol{J}, 50 \mu \mathrm{m}$. Sub, Subiculum; EntCX, entorhinal cortex; ONL, outer nuclear layer; INL, inner nuclear layer.

blot analysis illustrate the expected banding patterns for $C \ln 3^{+/+}$ and $C \ln 3^{\text {lacZ/+ }}$ littermates (Fig. $1 B$ ). Representative results of genomic PCR show the generation of correct size products for primer sets 1-3, for two mice each genotype (Fig. 1C). PCR products generated from primer sets 2 and 3 were sequenced and found to have the predicted sequence, confirming the fidelity of the recombination event at both $5^{\prime}$ and $3^{\prime}$ ends (data not shown).

Within the recombinant allele, the native $5^{\prime}$ region and the translational start is intact, and the nuclear-localized $\beta$-galactosidase coding region is fused in-frame to this ATG (Fig. $1 A)$. Thus, $\beta$-galactosidase expression should mimic that of CLN3, and $C \ln 3$ sequences should not be expressed. We used reverse transcription (RT)-PCR to test for mRNA encoding $\mathrm{CLN} 3$ in $C \ln 3^{+/+}, C \ln 3^{\text {lacZ/+}}$, and $C \ln 3^{\text {lac } Z / l a c Z}$ tissues. RNA was harvested from four separate brains regions of 2- to 3-month-old adult animals. RNA was reverse transcribed, and the cDNA was analyzed by PCR using a positive control primer set for the HPRT housekeeping transcript and a primer set to amplify the CLN3 coding region. As expected, $C \ln 3$ transcripts were detected in all $C \ln 3^{+1+}$ and $C \ln 3^{\text {lac } /+}$ samples but not detected in $C \ln 3^{\text {lacZ/lac } Z}$ tissues (Fig. 1D). QPCR analysis corroborated these results and determined that $C \ln 3$ transcript levels were twofold to threefold higher in $C \ln 3^{+/+}$compared with $C \ln 3^{\text {lacZ/+ }}$ samples and undetectable in $C \ln 3^{\text {lacZ/lacZ }}$ samples (Fig. $1 E$ ). Correspondingly, $\beta$-galactosidase transcripts were found to be twofold to threefold higher in $C \ln 3^{\text {lac } Z / l a c Z}$ compared with $C \ln 3^{\text {lac } Z /+}$ samples and undetectable in $C \ln 3^{+/+}$samples (Fig. $1 E$ ). These results clearly indicate a lack of $C \ln 3$ expression and acquired $\beta$-galactosidase expression from the recombinant allele. Finally, because stop codons as well as polyadenylation sequences for $\beta$-galactosidase and neomycin are present upstream of residual $C \ln 3$ sequences, it is highly unlikely that any CLN3 protein is translated from the recombinant locus. Thus, our $C \ln 3^{\text {lac } Z / l a c Z}$ mice are CLN3 null.

\section{Reporter gene expression in $C \ln 3^{\text {lacZ/+ }}$ mice}

Reporter expression in embryos was analyzed by X-gal staining of whole-mount cryosections from $C \ln 3^{\text {lac } /+}$ embryos at embry- onic day 9 (E9), E13, E15, and E17. Limited or no expression was detected at early time points (E9 and E13). At E15, reporter levels were striking in two cells types, vascular endothelial cells throughout the embryo, and fibroblasts of the developing lens (supplemental Fig. 1, available at www.jneurosci.org as supplemental material). Expression of CLN3 was either very low or undetectable in other tissues at E15. Expression persisted in the vascular endothelium and lens fibroblasts (data not shown) at E17 and appeared or intensified in several other cell types, most notably in epithelial cells lining the respiratory and gastrointestinal tracts (supplemental Fig. 2, available at www.jneurosci.org as supplemental material). In the developing E17 brain, cortical plate neurons were positive and were more heavily concentrated in the caudal regions of the plate (supplemental Fig. 2, available at www.jneurosci.org as supplemental material) and continued into the hippocampal formation. The $\mathrm{X}$-gal staining results from embryonic tissue sections are summarized in supplemental Table 1 (available at www.jneurosci.org as supplemental material).

In the postnatal brain, neuronal expression of $\beta$-galactosidase was detected in several regions. At postnatal day 7 (P7), expression was most extensive in neurons in the subiculum (Fig. 2A, B) and parasubiculum (data not shown) of the hippocampal formation and the deep layers of the entorhinal (Fig. $2 A, B$ ) and retrosplenial (data not shown) cortex. Mature neurons in the granule layer of the dentate gyrus in the P7 hippocampus were moderately positive and more prevalent in the caudal hippocampus (data not shown). By P21, reporter gene expression in these areas was similar or reduced compared with $\mathrm{P} 7$, with the exception of the dentate gyrus, in which $\beta$-galactosidase expression was enhanced (Fig. 2C). At P21 and P27, other areas with weak positive cells included the solitary tract region (Fig. 2D) and area postrema (Fig. 2E) of the rostral brainstem and regions of the amygdalohippocampal area and thalamus (data not shown). In adult mice, expression was no longer detectable in these areas, with the exception of weak signal in the area postrema (data not shown) and relatively high signal retained in the granule neurons of the dentate gyrus of the hippocampus, in which expression was noticeably more intense in the caudal aspect (Fig. $2 F$ ). Reporter expression in the adult brain was also evident in the median eminence (Fig. 2G). In the adult retina, staining for $\beta$-galactosidase activity revealed a subpopulation of positive cells within the inner nuclear layer, as well as weak expression in photoreceptor nuclei in the outer nuclear layer (Fig. $2 H$ ). Confocal microscopy after dual immunostaining for $\beta$-galactosidase and the neuronal marker NeuN confirmed that the majority of positive cells in the dentate gyrus were neurons (Fig. 2I).

Cells within the brain vasculature, as well as within the peripheral vasculature, were found to express $\beta$-galactosidase throughout development (supplemental Fig. 1, available at www. jneurosci.org as supplemental material) and in adulthood. Confocal analysis after dual staining for $\beta$-galactosidase and the endothelial cell surface marker CD31 shows $\beta$-galactosidasepositive nuclei within CD31-positive endothelial cells in a brain 
microvessel (Fig. 2J). Reporter expression was also detected in many cell types in tissues outside the CNS and was most prominent in epithelial cells of the proximal airway, gastrointestinal tract, and kidney, as well as low-level expression in endothelial cells lining vessels in diverse tissues (data not shown).

$C \ln 3^{\text {lacZ/acZ }}$ mice have NCL phenotypes A hallmark feature of the NCLs is autofluorescent storage material in cells (Wisniewski et al., 1988; Mitchison et al., 1999), and a common feature of many lysosomal storage diseases is secondary elevation of lysosomal enzymes. Both pathological features were detected in brains of the $C \ln 3^{\text {lac } Z / l a c Z}$ mice relative to $C \ln 3^{+/+}$ controls. The extent and distribution of autofluorescent storage accumulation was widespread in the $C \ln 3^{\text {lacZ/lacZ }}$ mice and increased with age and was absent or minimal in age-matched wild-type controls. Storage was most prominent and detected earliest in hippocampal neurons, particularly in the CA3 region (Fig. 3A). Other areas with notable autofluorescent accumulation included the thalamus (Fig. 3A), raphe nucleus, parasubiculum, presubiculum, red nucleus, and regions of the cerebral cortex (data not shown). Measurement of TPP1 activity was used as an indicator of compensatory upregulation of lysosomal enzyme activity, typical of many lysosomal storage disorders. TPP1 is deficient in the infantile form of NCL (Sleat et al., 1997), and TPP-1 activity was found previously to be enhanced in $C \ln 3^{\Delta e x I-6}$ mice (Mitchison et al., 1999) and in JNCL patients (Sleat et al., 1998). Cerebellar lysates from 1- and 6-month-old mice were analyzed for TPP1 activity (Fig. 3B). Whereas TPP1 levels increased over time for $C \ln 3^{+/+}$controls as well as $C \ln 3^{\text {lac Z /lacZ }}$ mice, this increase was much more dramatic in the $C \ln 3^{\text {lac } Z / l a c Z}$ mice (2.9-fold for $C \ln 3^{+/+}$compared with 6.8-fold for $C \ln 3^{\text {lac } Z / l a c Z}$ mice) (Fig. $3 B)$. Thus, our $C \ln 3^{\text {lac } Z / l a c Z}$ mice exhibit progressive pathological features in accordance with NCL phenotypes.

\section{$C \ln 3^{\text {lacZ/lacZ }}$ mice have progressive neurological deficits}

$C \ln 3^{\text {lac } Z / l a c Z}$ and $C \ln 3^{\text {lacZ/+ }}$ mice were tested for neurological dysfunction using a variety of assays. Motor function was assessed by the accelerating rotarod. As shown in Figure $4 A, C \ln 3^{\text {lac } Z / l a c Z}$ mice had no notable motor deficits at 1 month of age, but, by 2 months, $C \ln 3^{\text {lac } Z / l a c Z}$ mice were significantly impaired relative to their heterozygous littermates. Motor deficits continued to progress, and, by 10 months, $C \ln 3^{\text {lac } Z / l a c Z}$ mice were impaired to levels $50 \%$ of controls.

$C \ln 3^{\text {lacZ/+ }}$ and $C \ln 3^{\text {lacZ/lacZ }}$ mice were tested for a clasping phenotype indicative of neurological disease of a generalized nature (Mangiarini et al., 1996). We found that $40 \%$ of $C \ln 3^{\text {lacZ } / l a c Z}$ mice clasped by 4 months of age, and this number increased to $80 \%$ by 8 months of age. In contrast, none of the $C \ln 3^{\text {lac } Z /+}$ mice clasped at 4 months of age and only one at 8 months of age (Fig. 4B).

In a third assay, we assessed the overall activity of $C \ln 3^{\text {lac } Z / l a c z}$ mice relative to their $C \ln 3^{\text {lac } Z /+}$ littermates. Mice were given free access to an activity wheel for $4 \mathrm{~d}$, and revolutions during the nocturnal and daytime periods were recorded. At 2 months of age, there was no notable difference between $C \ln 3^{\text {lac } Z / l a c Z}$ and $C \ln 3^{\text {lac } Z /+}$ mice. At 10 months, $C \ln 3^{\text {lac } Z / l a c Z}$ mice exhibited $\sim 50 \%$ reduced nocturnal activity. Activity during the daylight hours remained low and unchanged for all groups over the testing period (Fig. 4C).

We noted that older $C \ln 3^{\text {lacZ/lac } Z}$ were tremulous, and we therefore performed tremor assays to quantify and monitor the phenotype over time. At 5 months of age, $C \ln 3^{\text {lac } Z / a c Z}$ animals had significantly higher tremor amplitude compared with $C \ln 3^{\text {lacZ/+ }}$ controls. At 10 and 12 months, this difference was more pronounced (Fig. 4D). Together, these data clearly demonstrate progressive neurological impairments and provide useful phenotypic information for screening therapeutic strategies.

\section{$C \ln 3^{\text {lacZ/lac } Z}$ mice have increased susceptibility to PTZ-induced seizures}

Seizures are a common feature of the NCLs. However, consistent with previous JNCL mouse models (Mitchison et al., 1999; Cotman et al., 2002), our $C \ln 3^{\text {lac } Z / l a c Z}$ animals display no overt spontaneous seizure behavior. To determine whether CLN3-deficient mice have altered susceptibility to pharmacologically induced seizures, we injected $C \ln 3^{\text {lac } Z / l a c Z}$ and control $C \ln 3^{+/+}$mice with $30 \mathrm{mg} / \mathrm{kg}$ PTZ, a dose known to induce modest to no seizure activity in wild-type C57BL/6 mice (D. Bonthius, personal communication). Latency to seizure, seizure duration, and grade of seizure were recorded. At this dose of PTZ, $50 \%$ of $\mathrm{Cln}^{+/+}$mice from the colony had no or very low seizure activity, whereas all $C \ln 3^{\text {lacZ/lac } Z}$ mice had grade 2 seizures or greater (Fig. $5 A$ ). $C \ln 3^{\text {lac } Z / l a c Z}$ mice also developed seizures more quickly (93.8 \pm 6.5 vs $196.2 \pm 19.7 \mathrm{~s} ; p<0.005)$, and the seizures lasted longer relative to normal controls $(425 \pm 70.3$ vs $202.5 \pm 40.9 \mathrm{~s}$; $p<0.05)$.

To test whether seizure activity induced CLN3 promoter activity, a cohort of $\mathrm{Cln} 3^{\text {lacZ/+ }}$ animals were subjected to seizure induction, and brains were removed and processed for $\beta$-galactosidase histochemistry. As shown in Figure $5 B$, $\beta$-galactosidase activity, as detected by $\mathrm{X}$-gal histochemistry, was visibly enhanced in granule neurons of the dentate gyrus (Fig. 5B) and microvasculature (data not shown) of brains from PTZtreated $(50 \mathrm{mg} / \mathrm{kg}) C \ln 3^{\text {lacZ/+ }}$ mice relative to saline-treated $\mathrm{Cln} 3^{\text {lac } /+}$ mice. Together, these results indicate a relationship between seizure activity and CLN3 expression levels in the brain and suggest a role for CLN3 in inhibiting or dampening seizure activity. 
A

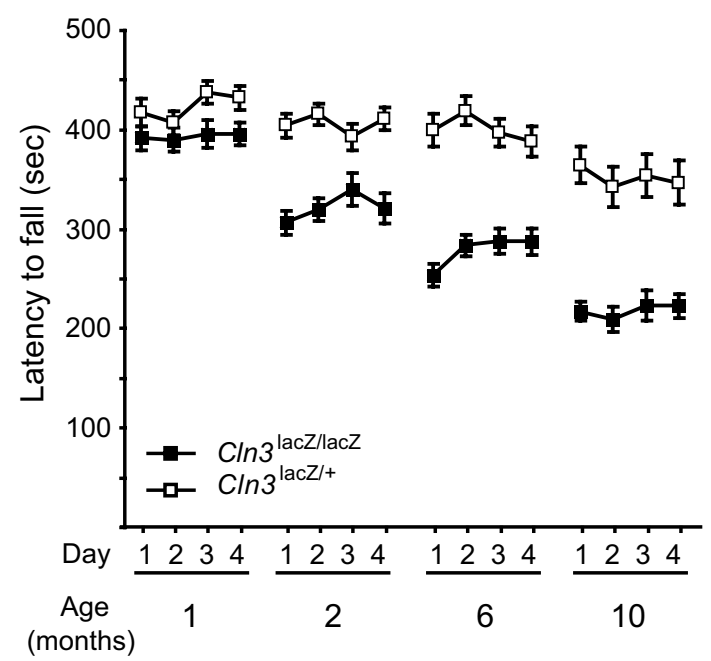

B
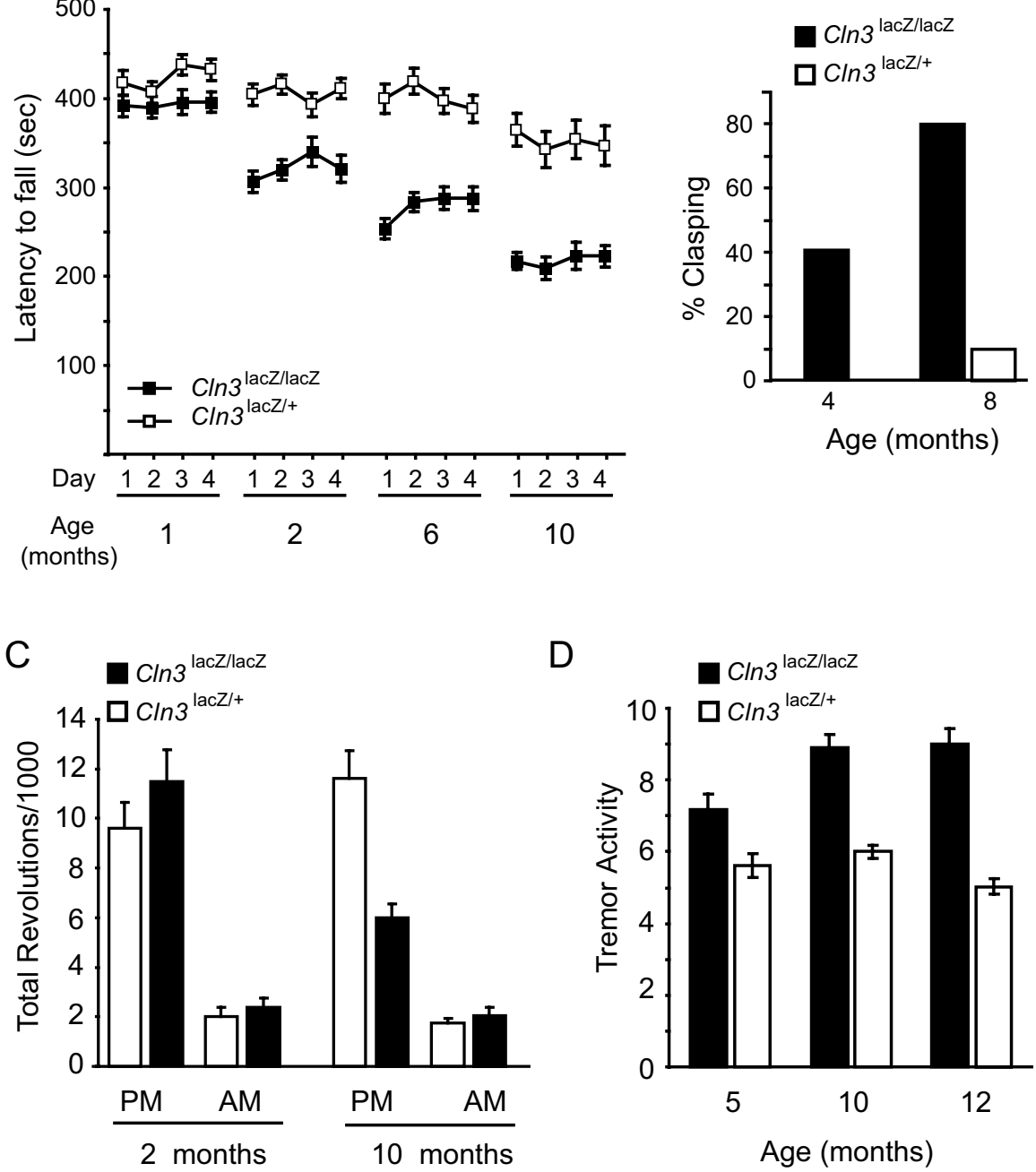

Figure 4. $\quad C \ln 3^{\mathrm{lac} Z / \mathrm{lac} Z}$ mice have progressive behavioral deficits relative to age-matched $\ln 3^{\mathrm{lac} Z /+}$ control littermates. $\boldsymbol{A}$, The rotarod assay was performed at the ages indicated and at 2,6, and 10 months of age, Cln $3^{\text {lacz/lacz }}$ mice exhibited significant impairment at all days tested ( $n=11$ for each genotype; $p<0.005$ ). B, Nearly all CIn3 lacz/lacZ mice display a clasping phenotype by 8 months of age ( $n=11$ for each genotype). $C, C \ln 3^{\text {lacz/lacZ }}$ mice show reduced nocturnal activity at 10 months of age compared with 2 months of age, and, at 10 months, the activity level of $C \ln 3^{\text {lacz/lacz }}$ mice is significantly lower than $C \ln 3^{\text {lacz/+ }} \operatorname{controls}(n=$ 11 for each genotype; $p<0.005$ at 10 months). $D,\left(\ln 3^{\text {lacz/lacz }}\right.$ mice have a significant tremor phenotype relative to control mice ( $n=11$ for each genotype; $p<0.005$ at all time points).

\section{Discussion}

In this study, we developed a reporter knock-in mouse as a tool for evaluating developmental and adult expression of $\mathrm{Cln} 3$ and to study the behavior of the CLN3-deficient mouse. Evaluation of reporter activity in our $C \ln 3^{\text {lac } Z /+}$ and $C \ln 3^{\text {lac } Z / l a c Z}$ reporter mice provides a comprehensive detailing of CLN3 expression in embryonic and adult CNS and peripheral tissues. Moreover, characterization of our CLN3-deficient mice revealed CNS pathology and neurological deficits consistent with JNCL. Thus, our mouse model provides us with a unique model to study JNCL progression in relation to reporter expression.

In adult murine brain, staining for $\beta$-galactosidase activity indicated reporter expression in granule neurons of the dentate gyrus as well as in vascular endothelium. This is consistent with reported in situ detection of $C \ln 3$ transcripts in granule neurons of the dentate gyrus in the mouse (Luiro et al., 2001) and immunodetection of CLN3 in human brain endothelial cells (Margraf et al., 1999). Staining was below detection level in several neuro- nal populations reported by others to be CLN3 positive, such as cerebellar neurons, neurons of the thalamus, hypothalamus, and some hippocampal regions (Luiro et al., 2001; Cotman et al., 2002). These discrepancies may relate to disparate transcript stabilities between $\beta$-galactosidase and native CLN3 and/or differences in the sensitivities or specificities of the reagents used.

In the developing brain, we detected reporter expression in several embryonic and early postnatal neuronal populations. Despite this expression, our mouse model revealed no early postnatal motor/behavioral impairments. Similarly, pups from the $C \ln 3^{\Delta e x 7 / 8}$ (Katz et al., 1999; Cotman et al., 2002) and $C \ln 3^{\Delta \operatorname{exl-6}}$ (Mitchison et al., 1999) mouse models display no gross abnormalities in brain architecture or early behavioral deficits. JNCL patients likewise acquire normal intelligence and neurological functions in infancy and toddler years. However, it is possible that CLN3 is important for subtle aspects of neuronal development, such that behavioral abnormalities are subclinical at early time points. It is also possible that a cumulative toxic effect, attributable to nonfunctional or absent CLN3, begins during embryogenesis in some cell types and later reaches a threshold to cause neuronal dysfunction. Alternatively, CLN3 may perform a redundant function during development but a unique and indispensable function in mature neurons.

In the adult brain, $\beta$-galactosidase expression declined in all regions, with retention limited primarily to neurons in the granule cell layer of the hippocampal dentate gyrus. The dentate gyrus is a highly plastic area, in which new neurons are born throughout life and synapses are continually modified during learning/ memory processes (Lynch, 2004). Thus, CLN3 expression may play a role in neuronal maturation, neurite extension, or synapse formation or modification. Moreover, abnormal activity in the hippocampus is believed to underlie many forms of seizures (McCormick and Contreras, 2001). Thus, intact CLN3 function may be necessary for modulating conductive activity in the hippocampus.

Seizures are a common feature of most NCLs. JNCL patients suffer from severe and progressive seizures. A previous report found that CLN8 expression in the hippocampus increased in response to kindling seizure induction (Lonka et al., 2005). The mouse NCL gene $C \ln 8$ is developmentally regulated in mouse brain and upregulated in the hippocampal kindling model of epilepsy. Similarly, we demonstrated elevated reporter protein levels after PTZ-induced seizures. We further demonstrated that our CLN3-deficient mice have an increased sensitivity to PTZinduced seizures compared with wild-type controls. Latency to seizure was reduced, and the frequency, duration, and grade of seizure were all enhanced in $C \ln 3^{\text {lacZ/lac } Z}$ mice. A previous report 
examined inhalant-induced seizures in the $C \ln 3^{\Delta e x 1-6}$ model and found adult $C \ln 3^{\Delta e x 1-6}$ mice to be more vulnerable to death compared with age-matched controls (Kriscenski-Perry et al., 2002). Interestingly, they found latency to seizure to be increased in young (25-42 d old) $C \ln 3^{\Delta e x 1-6}$ mice compared with controls, an age group we did not analyze.

Malfunction of dentate gyrus neurons may contribute to seizure activity and mental deterioration observed in Batten disease and in our mouse model. Granule neurons relay information from the cortex to the CA3 region. In our JNCL mouse model and that of others, autofluorescent storage appears relatively early and is abundant in the hippocampus, particularly in the CA3 region, and it has been reported that hippocampal interneuron populations are reduced in older $C \ln 3^{\Delta e x 1-6}$ mice (Pontikis et al., 2004). Moreover, postmortem analysis of latestage JNCL patient brains reveals striking neuronal loss in hippocampal CA3 and CA2 regions and relative sparing of CA1

(Haltia et al., 2001; Tyynela et al., 2004). It is possible that malfunctioning CLN3-deficient granule neurons create an excitatory/inhibitory imbalance in the hippocampus, enhancing seizure susceptibility and precipitating excitotoxicity.

JNCL patients show significant declines in motor ability beginning in early childhood. We tested several measures of locomotion/coordination in our mouse model from 1 to 12 months of age: rotarod analysis, total activity using a running wheel system, the clasp assay, and resting tremor amplitude. We detected motor deficits in $C \ln 3^{\text {lac } / l a c Z}$ mice on the accelerating rotarod by 2 months of age, with continued decline for the duration of the study. Rotarod deficits can be caused by cerebellar or cortical dysfunction and can be influenced by deficits in learning. The total activity of $C \ln 3^{\text {lac } Z / l a c Z}$ mice also was significantly reduced, and nearly all $C \ln 3^{\text {lac } Z / l a c Z}$ mice clasp when suspended by the tail by 8 months of age. In addition, the $C \ln 3^{\text {lac } Z / l a c Z}$ mice demonstrated a resting tremor that worsened with age. The progressive behavioral deficits in the $C \ln 3^{\text {lac } Z / l a c Z}$ mouse model mirror many aspects of JNCL and provide important benchmarks by which to assess potential therapies.

Visual impairment occurs early in JNCL patients, progresses to blindness, and is associated with neuronal loss throughout the retina (Bensaoula et al., 2000). In contrast to the human disease, photoreceptor loss is minimal in mouse models (Cotman et al., 2002; Seigel et al., 2002) and ERGs remain normal (Seigel et al., 2002). Nonetheless, significant retinal inclusions occur in these mouse models, as well as in human JNCL ocular tissue (Bensaoula et al., 2000). The discrepancy between the extent of photoreceptor loss in patients versus mouse models may reflect the shorter lifespan of the mouse. Alternatively, as suggested in a recent study (Weimer et al., 2006), loss of retinal neurons may be secondary to neuronal loss in visual centers, which differ between mouse and human. In $C \ln 3^{\text {lacZ/lac } Z}$ mice, we clearly detect reporter expression in the retina. Although there are no obvious signs of visual problems, we have not yet assessed the retinas of $C \ln 3^{\text {lacZ/lac } Z}$ mice ultrastructurally or by electrophysiology.

Of potential importance to Batten disease is the finding that
B

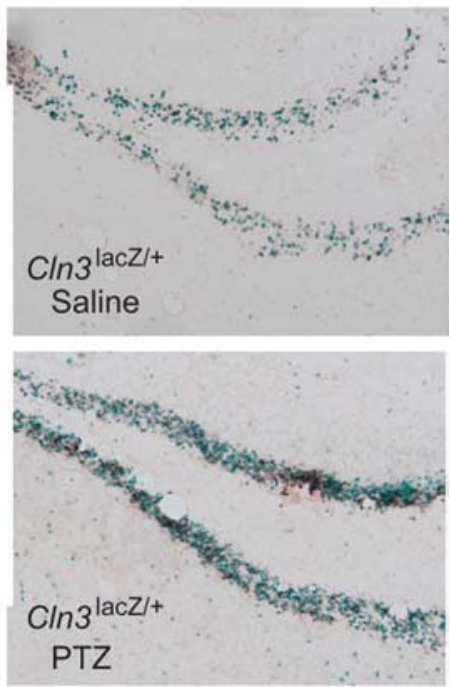

Cln $3^{\text {lacz/lacz }}$ and $\mathrm{Cln} 3^{+/+}$mice were given PTZ at 30 $\mathrm{mg} / \mathrm{kg}$, and seizure onset, grade, and duration were recorded ( $n=10$ for each genotype). $A$, PTZ induced no to moderate seizures in wild-type mice, although the effect was more severe in $\mathrm{Cln}^{\text {lacz/lacZ }}$ mice. $\boldsymbol{B}$, Histochemistry for $\beta$-galactosidase shows enhanced reporter expression in the hippocampus of a PTZ (50 mg/kg dose)-injected (bottom) compared with a control salineCLN3 is expressed in endothelia throughout the brain vasculature. In human brain, CLN3 has similarly been localized to endothelial cells (Margraf et al., 1999). In the $C \ln 3^{\Delta e x 1-6}$ mouse, mast cell infiltration occurs in the optic nerve, indicating loss of blood-brain barrier (BBB) at this site (Sappington et al., 2003). Furthermore, autoantibodies to GAD65, an enzyme involved in synthesis of the neurotransmitter GABA, are found in the sera from Batten disease mouse models (Chattopadhyay et al., 2002) and JNCL patients (Ramirez-Montealegre et al., 2005). This may reflect loss of barrier integrity and consequent GAD65 exposure to the immune system. Indeed, evidence of impaired barrier function has been reported recently for the $C \ln 3^{\Delta e x 1-6}$ mouse model (Lim et al., 2007). Thus, loss of a basic function performed by CLN3 in brain endothelial cells might compromise the integrity of the BBB and contribute to JNCL pathology.

The molecular function of CLN3 has not been elucidated. Studies in yeast indicate roles in maintenance of vacuolar arginine levels, pH, and/or ion homeostasis (Pearce et al., 1999; Chattopadhyay et al., 2000; Kim et al., 2003, 2005). A recent report indicates that, similar to yeast cells, arginine transport into lysosomes is defective in JNCL patient-derived lymphoblasts (Ramirez-Montealegre and Pearce, 2005). Other studies with human fibroblasts indicate CLN3 involvement in lysosomal $\mathrm{pH}$ maintenance and degradation (Golabek et al., 2000) and endocytosis (Luiro et al., 2004). Cells derived from $C \ln 3^{\Delta e x 7 / 8}$ mice display defects in endosome-to-lysosome vesicular trafficking and mitochondrial function (Fossale et al., 2004), and microarray analysis of neurons from $C \ln 3^{\Delta e x 7 / 8}$ mice reveals altered levels of transcripts coding for proteins involved in synaptic, cytoskeletal, and metabolic functions (Luiro et al., 2006). In addition, a recent study indicates that CLN3 may impact palmitoyl desaturation (Narayan et al., 2006). It is interesting to speculate that, by modifying palmitoyl saturation, CLN3 may influence microdomain localization of proteins within the plasma membrane or intracellular membranes. Relatively high expression of reporter in neurons, endothelial cells, and epithelial cells would certainly be con- 
sistent with a role for CLN3 in modulating the endocytic/exocytic movement of receptors, channels, or transporters.

To understand how to treat and ultimately cure JNCL patients, we must have a better understanding of the developmental pattern and tissue distribution of CLN3. Our reporter mouse has helped identify key prenatal and postnatal CLN3-expressing cell types in the CNS. Moreover, our reporter mouse model gives us a tool to correlate CLN3 expression and regional localization with motor and behavioral deficits. This information is critical to the development of small molecule or gene replacement strategies for this integral membrane protein and will aid in the elucidation of CLN3 function and the pathogenesis of Batten disease.

\section{References}

Ausubel F, Brent R, Kingston R, Moore D, Seidman J, Smith J, Struhl K, Albright L, Coen D, Varki A, eds (1998) Current protocols in molecular biology. New York: Wiley.

Bensaoula T, Shibuya H, Katz ML, Smith JE, Johnson GS, John SK, Milam AH (2000) Histopathologic and immunocytochemical analysis of the retina and ocular tissues in Batten disease. Ophthalmology 107:1746-1753.

Chattopadhyay S, Muzaffar NE, Sherman F, Pearce DA (2000) The yeast model for batten disease: mutations in BTN1, BTN2, and HSP30 alter pH homeostasis. J Bacteriol 182:6418-6423.

Chattopadhyay S, Ito M, Cooper JD, Brooks AI, Curran TM, Powers JM, Pearce DA (2002) An autoantibody inhibitory to glutamic acid decarboxylase in the neurodegenerative disorder Batten disease. Hum Mol Genet 11:1421-1431.

Cotman SL, Vrbanac V, Lebel LA, Lee RL, Johnson KA, Donahue LR, Teed AM, Antonellis K, Bronson RT, Lerner TJ, MacDonald ME (2002) Cln3(Delta ex7/8) knock-in mice with the common JNCL mutation exhibit progressive neurologic disease that begins before birth. Hum Mol Genet 11:2709-2721.

Ezaki J, Takeda-Ezaki M, Koike M, Ohsawa Y, Taka H, Mineki R, Murayama K, Uchiyama Y, Ueno T, Kominami E (2003) Characterization of Cln3p, the gene product responsible for juvenile neuronal ceroid lipofuscinosis, as a lysosomal integral membrane glycoprotein. J Neurochem 87:1296-1308.

Fossale E, Wolf P, Espinola JA, Lubicz-Nawrocka T, Teed AM, Gao H, Rigamonti D, Cattaneo E, MacDonald ME, Cotman SL (2004) Membrane trafficking and mitochondrial abnormalities precede subunit c deposition in a cerebellar cell model of juvenile neuronal ceroid lipofuscinosis. BMC Neurosci 5:57.

Golabek AA, Kida E, Walus M, Kaczmarski W, Michalewski M, Wisniewski KE (2000) CLN3 protein regulates lysosomal $\mathrm{pH}$ and alters intracellular processing of Alzheimer's amyloid-beta protein precursor and cathepsin D in human cells. Mol Genet Metab 70:203-213.

Haltia M, Herva R, Suopanki J, Baumann M, Tyynela J (2001) Hippocampal lesions in the neuronal ceroid lipofuscinoses. Eur J Paediatr Neurol 5 [Suppl A]:209-211.

Harper SQ, Staber PD, He X, Eliason SL, Martins I, Mao Q, Yang L, Kotin RM, Paulson HL, Davidson BL (2005) RNA interference improves motor and neuropathological abnormalities in a Huntington's disease mouse model. Proc Natl Acad Sci USA 102:5820-5825.

Haskell RE, Carr CJ, Pearce DA, Bennett MJ, Davidson BL (2000) Batten Disease: Evaluation of CLN3 mutations on protein trafficking and function. Hum Mol Genet 9:735-744

Katz ML, Shibuya H, Liu P-C, Kaur S, Gao C-L, Johnson GS (1999) A mouse gene knockout model for juvenile ceroid-lipofuscinosis (Batten Disease). J Neurosci Res 57:551-556.

Kim Y, Ramirez-Montealegre D, Pearce DA (2003) A role in vacuolar arginine transport for yeast Btn $1 \mathrm{p}$ and for human CLN3, the protein defective in Batten disease. Proc Natl Acad Sci USA 100:15458-15462.

Kim Y, Chattopadhyay S, Locke S, Pearce DA (2005) Interaction among Btnlp, Btn2p, and Ist2p reveals potential interplay among the vacuole, amino acid levels, and ion homeostasis in the yeast Saccharomyces cerevisiae. Eukaryot Cell 4:281-288.

Kriscenski-Perry E, Applegate CD, Serour A, Mhyre TR, Leonardo CC, Pearce DA (2002) Altered flurothyl seizure induction latency, phenotype, and subsequent mortality in a mouse model of juvenile neuronal ceroid lipofuscinosis/batten disease. Epilepsia 43:1137-1140.

Kyttala A, Ihrke G, Vesa J, Schell MJ, Luzio JP (2004) Two motifs target
Batten disease protein CLN3 to lysosomes in transfected nonneuronal and neuronal cells. Mol Biol Cell 15:1313-1323.

Lerner TJ, Boustany RMN, Anderson JW, D’Arigo KL, Schlumpf K, Buckler AJ, Gusella JF, Haines JL, Kremmidiotis G, Lensink IL, Sutherland GR, Callen DF, Taschner PEM, De Vos N, Van Ommen GJB, Breuning MH, Doggett NA, Meincke LJ, Liu ZY, Goodwin LA, Tesmer JG, Mitchison HM, O'Rawe AM, Munroe PB (1995) Isolation of a novel gene underlying Batten disease, CLN3. Cell 82:949-957.

Levkovitz Y, Avignone E, Groner Y, Segal M (1999) Upregulation of GABA neurotransmission suppresses hippocampal excitability and prevents long-term potentiation in transgenic superoxide dismutaseoverexpressing mice. J Neurosci 19:10977-10984.

Lim MJ, Alexander N, Benedict JW, Chattopadhyay S, Shemilt SJ, Guerin CJ, Cooper JD, Pearce DA (2007) IgG entry and deposition are components of the neuroimmune response in Batten disease. Neurobiol Dis 25:239-251.

Lin L, Sohart I, Lackland H, Lobel P (2001) The human CLN2 protein/ tripeptidyl-peptidase I is a serine protease that autoactivates at acidic $\mathrm{pH}$. J Biol Chem 276:2249-2255.

Lonka L, Aalto A, Kopra O, Kuronen M, Kokaia Z, Saarma M, Lehesjoki AE (2005) The neuronal ceroid lipofuscinosis Cln8 gene expression is developmentally regulated in mouse brain and up-regulated in the hippocampal kindling model of epilepsy. BMC Neurosci 6:27.

Luiro K, Kopra O, Lehtovirta M, Jalanko A (2001) CLN3 protein is targeted to neuronal synapses but excluded from synaptic vesicles: new clues to Batten disease. Hum Mol Genet 10:2123-2131.

Luiro K, Yliannala K, Ahtiainen L, Maunu H, Jarvela I, Kyttala A, Jalanko A (2004) Interconnections of CLN3, Hook1 and Rab proteins link Batten disease to defects in the endocytic pathway. Hum Mol Genet 13:3017-3027.

Luiro K, Kopra O, Blom T, Gentile M, Mitchison HM, Hovatta I, Tornquist K, Jalanko A (2006) Batten disease (JNCL) is linked to disturbances in mitochondrial, cytoskeletal, and synaptic compartments. J Neurosci Res 84:1124-1138.

Lynch MA (2004) Long-term potentiation and memory. Physiol Rev 84:87-136.

Mangiarini L, Sathasivam K, Seller M, Cozens B, Harper A, Hetherington C, Lawton M, Trottier Y, Lehrach H, Davies SW, Bates GP (1996) Exon 1 of the HD gene with an expanded CAG repeat is sufficient to cause a progressive neurological phenotype in transgenic mice. Cell 87:493-506.

Mao Q, Xia H, Davidson B (2003) Intracellular trafficking of CLN2, the protein underlying the childhood neurodegenerative disease, Batten disease. FEBS Lett 555:351-357.

Margraf LR, Boriack RL, Routheut AAJ, Cuppen I, Alhilali L, Bennett CJ, Bennett MJ (1999) Tissue expression and subcellular localion of CLN3, the Batten disease protein. Mol Genet Metab 66:283-289.

McCormick DA, Contreras D (2001) On the cellular and network bases of epileptic seizures. Annu Rev Physiol 63:815-846.

Mitchison HM, Bernard DJ, Greene ND, Cooper JD, Junaid MA, Pullarkat RK, de Vos N, Breuning MH, Owens JW, Mobley WC, Gardiner RM, Lake BD, Taschner PE, Nussbaum RL (1999) Targeted disruption of the Cln3 gene provides a mouse model for Batten disease. The Batten Mouse Model Consortium [corrected]. Neurobiol Dis 6:321-334.

Narayan SB, Rakheja D, Tan L, Pastor JV, Bennett MJ (2006) CLN3P, the Batten's disease protein, is a novel palmitoyl-protein Delta-9 desaturase. Ann Neurol 60:570-577.

Pearce DA, Ferea T, Nosel SA, Das B, Sherman F (1999) Action of Btn1p, the yeast ortholog of the human Batten disease gene. Nat Genet 22:55-58.

Pontikis CC, Cella CV, Parihar N, Lim MJ, Chakrabarti S, Mitchison HM, Mobley WC, Rezaie P, Pearce DA, Cooper JD (2004) Late onset neurodegeneration in the $\mathrm{Cln} 3-/-$ mouse model of juvenile neuronal ceroid lipofuscinosis is preceded by low level glial activation. Brain Res 1023:231-242.

Ramirez-Montealegre D, Pearce DA (2005) Defective lysosomal arginine transport in juvenile Batten disease. Hum Mol Genet 14:3759-3773.

Ramirez-Montealegre D, Chattopadhyay S, Curran TM, Wasserfall C, Pritchard L, Schatz D, Petitto J, Hopkins D, She JX, Rothberg PG, Atkinson M, Pearce DA (2005) Autoimmunity to glutamic acid decarboxylase in the neurodegenerative disorder Batten disease. Neurology 64:743-745.

Sambrook J, Fritsch EF, Maniatis T (1989) Molecular cloning: a laboratory manual. Plainview, NY: Cold Spring Harbor Laboratory. 
Santavuori P (1988) Neuronal ceroid-lipofuscinoses in childhood. Brain Dev 10:80-82.

Sappington RM, Pearce DA, Calkins DJ (2003) Optic nerve degeneration in a murine model of juvenile ceroid lipofuscinosis. Invest Ophthalmol Vis Sci 44:3725-3731.

Seigel GM, Lotery A, Kummer A, Bernard DJ, Greene ND, Turmaine M, Derksen T, Nussbaum RL, Davidson B, Wagner J, Mitchison HM (2002) Retinal pathology and function in a Cln3 knockout mouse model of juvenile Neuronal Ceroid Lipofuscinosis (batten disease). Mol Cell Neurosci 19:515-527.

Sleat DE, Donnelly RJ, Lackland H, Liu CG, Sohar I, Pullarkat RK, Lobel P (1997) Association of mutations in a lysosomal protein with classical late-infantile neuronal ceroid lipofuscinosis. Science 277:1802-1805.

Sleat DE, Sohar I, Pullarkat PS, Lobel P, Pullarkat RK (1998) Specific alterations in levels of mannose 6-phosphorylated glycoproteins in different neuronal ceroid lipofuscinoses. Biochem J 334:547-551.
Tyynela J, Cooper JD, Khan MN, Shemilts SJ, Haltia M (2004) Hippocampal pathology in the human neuronal ceroid-lipofuscinoses: distinct patterns of storage deposition, neurodegeneration and glial activation. Brain Pathol 14:349-357.

Weimer JM, Custer AW, Benedict JW, Alexander NA, Kingsley E, Federoff HJ, Cooper JD, Pearce DA (2006) Visual deficits in a mouse model of Batten disease are the result of optic nerve degeneration and loss of dorsal lateral geniculate thalamic neurons. Neurobiol Dis 22:284-293.

Wisniewski KE, Rapin I, Heaney-Kieras J (1988) Clinico-pathological variability in the childhood neuronal ceroid-lipofuscinoses and new observations on glycoprotein abnormalities. Am J Med Genet [Suppl] 5:27-46.

Xia H, Mao Q, Eliason SL, Harper SQ, Martins IH, Orr HT, Paulson HL, Yang L, Kotin RM, Davidson BL (2004) RNAi suppresses polyglutamine-induced neurodegeneration in a mouse model of SCA1. Nat Med 10:816-820. 